\title{
Squamous cell carcinoma developing in an intracranial epidermoid cyst (cholesteatoma)
}

\author{
H. FOX AND E. A. SOUTH
}

\section{From the Departments of Pathology and Neurosurgery, Manchester Royal Infirmary}

Epidermoid cysts are estimated to form 0.5 to $1 \%$ of all intracranial tumours (Russell and Rubinstein, 1963). The most common sites of occurrence are in the cerebellopontine angle and in the para-pituitary area but a small number of intracerebral and intraventricular tumours have been recorded (Peyton and Baker, 1942). The cysts contain structureless, waxy, keratinous material and their wall is formed by a thin layer of squamous epithelium in which dermal elements are not present. Malignant change in the squamous lining of these cysts is extremely rare and only eight cases have been recorded in the literature. It is thought of interest, therefore, to report the following case in which a squamous cell carcinoma developed in a longstanding intraventricular epidermoid cyst.

\section{CASE REPORT}

In February 1955 a man (55/10581), aged 43 years, presented with an 18-month history of increasing clumsiness of the right hand, deterioration in writing, increasing 'tiredness' of the right leg, and slightly defective memory.

On examination he was found to have a right facial weakness of the upper motor neurone type, right homonymous hemianopia, and rapid nystagmus on looking both to right and left. There was a slight increase in tone in the right side of the body and the right superficial abdominal reflexes were absent.

Laboratory tests, including cerebrospinal fluid examination, were negative, and a chest radiograph showed only bronchitic changes with pleural thickening. A left carotid angiogram showed a large anterior temporal space-occupying lesion; therefore in May 1955 a left temporal craniotomy was performed. On entering the temporal lobe the lateral ventricle was found to be greatly dilated and packed nearly solid with the characteristic white waxy flakes of an epidermoid cyst. The tumour extended antero-medially through the choroidal fissure and into the basal cisterns. The flakes of keratin were dissected free and sucked out, but the close adherence of the outer membrane to the ependyma and choroid plexus made total removal impossible. Histological examination of the removed material showed that the 'cyst' was lined by a thin regular squamous epithelium showing no evidence of malignancy (Fig. 1). The cyst was filled with keratinized squames.
The patient made a good recovery and post-operativel $f_{6}^{\frac{?}{6}}$ showed only a little incoordination of the right arm and slight restriction of the right temporal field and fin nystagmus. On discharge three weeks later the only abnormality was some restriction of the right tempora field.

A week later the patient was readmitted with meningitis. No organisms were isolated from the cerebrospinal fluid? He was treated with intravenous suphonamides and intra $\exists$ thecal penicillin and streptomycin, and recovered aftefs two weeks. This was thought to be a sterile meningitis of the type known to complicate operative procedures upong an epidermoid cyst.

Six months later the patient had a severe epileptio

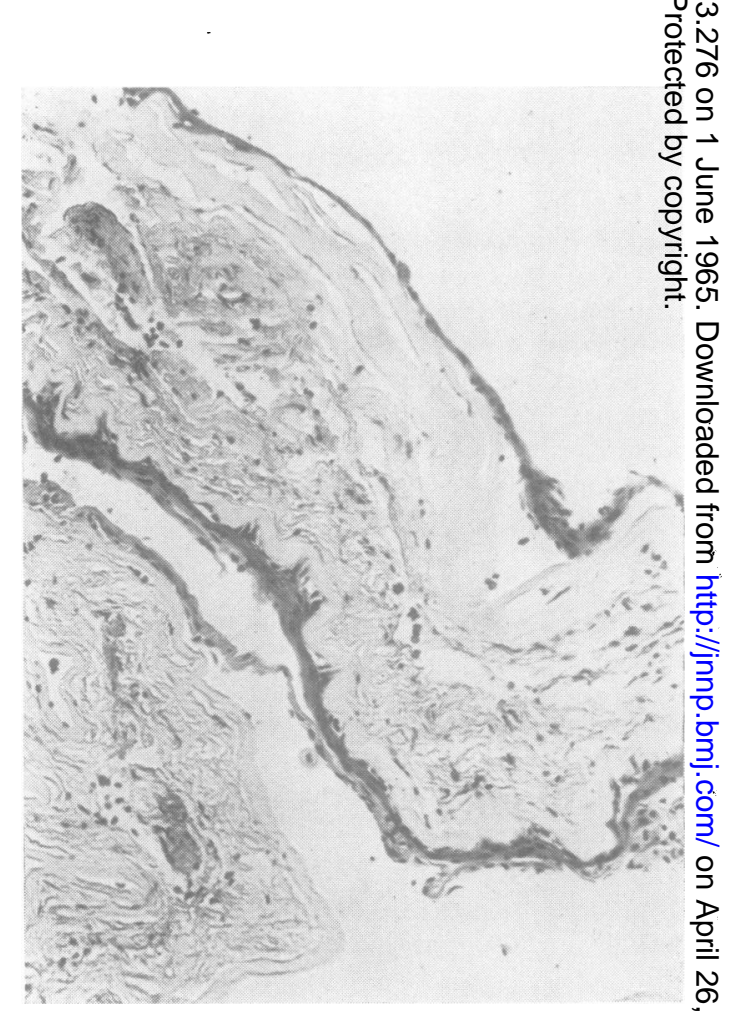

FIG. 1. Biopsy of cyst wall in 1955. The cyst is lined by flattened but regular squamous epithelium. Haematoxylin w and eosin $\times 60$. 
attack with dysphasia and right-sided signs. Anticonvulsants were prescribed and the patient remained relatively well for the next two years. He then began to complain of intermittent occipital headaches and occasional transient difficulties with his speech.

In July 1958 he was again admitted, complaining of backache, occipital headache, and a stiff neck. On clinical examination he was found to have nystagmus and restriction of the upper quadrant of the right visual field. An air encephalogram revealed extensive recurrence of the tumour above and anterior to the left petrous bone. A left temporal craniotomy was again performed and little evidence of residual tumour was found in the lateral ventricle. By exploring the middle fossa, however, a tumour was seen in the cisterna chiasmatica and around the pons. The tumour was partially removed and histological examination of the removed fragments showed only keratin.

The patient was discharged three months postoperatively with a left ptosis as the only abnormal sign. Within the next few months he developed a left sixth nerve palsy with diplopia and left frontal headaches. It was thought that these symptoms indicated extension of the tumour beneath the tentorium cerebelli. The patient was therefore submitted in January 1959 to posterior fossa exploration. On this occasion the tumour was found involving the left cerebellar hemisphere and there was extensive tumour infiltration around the brainstem. Despite this spread of the tumour there was no change in the histological appearances of the keratinous tissue removed at operation. This still appeared completely benign.

The patient's post-operative condition was poor; he became very depressed, complaining continually of dizzyness, diplopia, and headaches. The left sixth and seventh nerves were now paralysed but there was no recurrence of incoordination. The patient was discharged after three months.

On routine follow-up his symptoms were worse and there were signs of pyramidal tract involvement. Nevertheless the patient remained moderately well until November 1962, when he rapidly deteriorated and returned complaining of dizzyness, right-sided deafness, headache, and ataxia. On examination he had a right temporal field loss, nystagmus, a left sixth nerve palsy, and ataxic gait. Whilst awaiting operation the right seventh nerve became paralysed. Air encephalography suggested the presence of tumour in the pontine fossa anterior to the pons. A combined posterior fossa exploration and temporal craniotomy revealed a layer of tumour invading the most medial aspect of the temporal lobe and extending into the basal cisterns down in front of the pons and brainstem. A small amount of tumour was removed with difficulty from the temporal lobe (the difficulty being due to dense fibrous adhesions) but little else could be achieved. Histological examination of the removed tissue showed much acellular keratin and pieces of squamous epithelium. The squamous epithelial cells showed considerable pleomorphism and were very poorly differentiated. The nuclei were irregular, enlarged, and hyperchromatic and several mitotic figures were seen (Fig. 2). The appearances were in marked contrast to those of the first

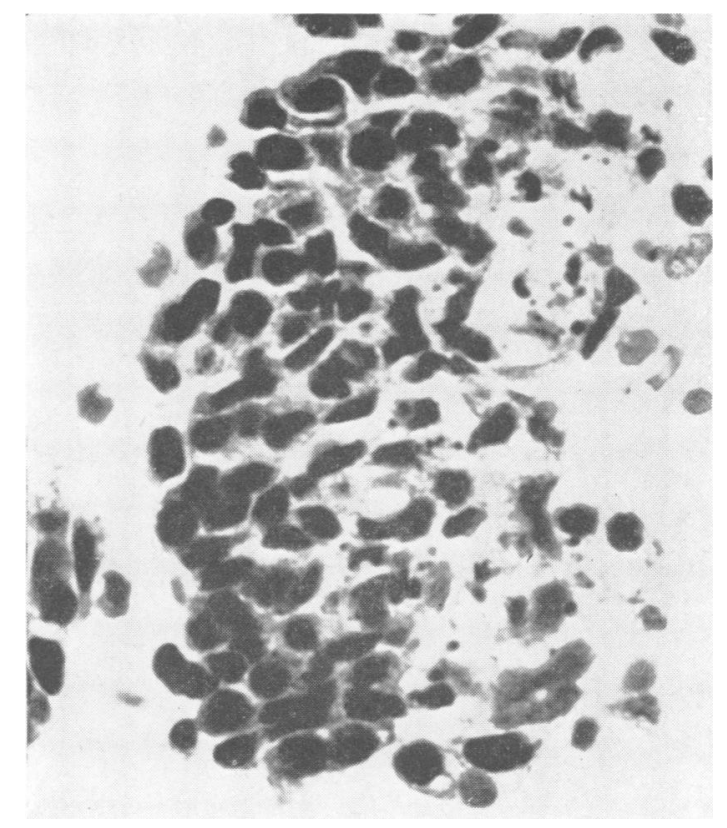

FIG. 2. Biopsy of tumour in 1962. The cells are poorly differentiated with hyperchromatic pleomorphic nuclei. Haematoxylin and eosin $\times 850$.

biopsy specimen and it was considered that a squamous cell carcinoma had developed.

Postoperatively the patient remained very ill and developed bilateral corneal ulceration, a bulbar palsy, and bronchopneumonia. He died, without recovering consciousness, six weeks later in January 1963.

\section{NECROPSY FINDINGS}

The immediate cause of death was a severe bronchopneumonia, but apart from this the abnormal findings were confined to the brain. No evidence of neoplasm was found outside the central nervous system.

In the cranial cavity the dura overlying the left temporal lobe was thickened and fibrous. The left temporal lobe and left cerebellar hemisphere had been partially removed. There was a firm whitish grey plaque of tumour tissue extending from the chiasma back over the pons to the medulla filling the basal and lateral cisterns (Fig. 3). The basilar artery was completely surrounded by tumour from which it could not be dissected (Fig. 4). On cutting the brain, greyish tumour tissue was seen in the anterior part of the medial surface of the left temporal lobe and this was in continuity with the basal tumour mass. No other evidence of residual tumour was seen in the ventricles, cerebral hemispheres, or cerebellum.

\section{HISTOLOGICAL APPEARANCES}

There was a diffuse carcinomatous infiltration of the meninges in the middle fossa, and the thickened dura 

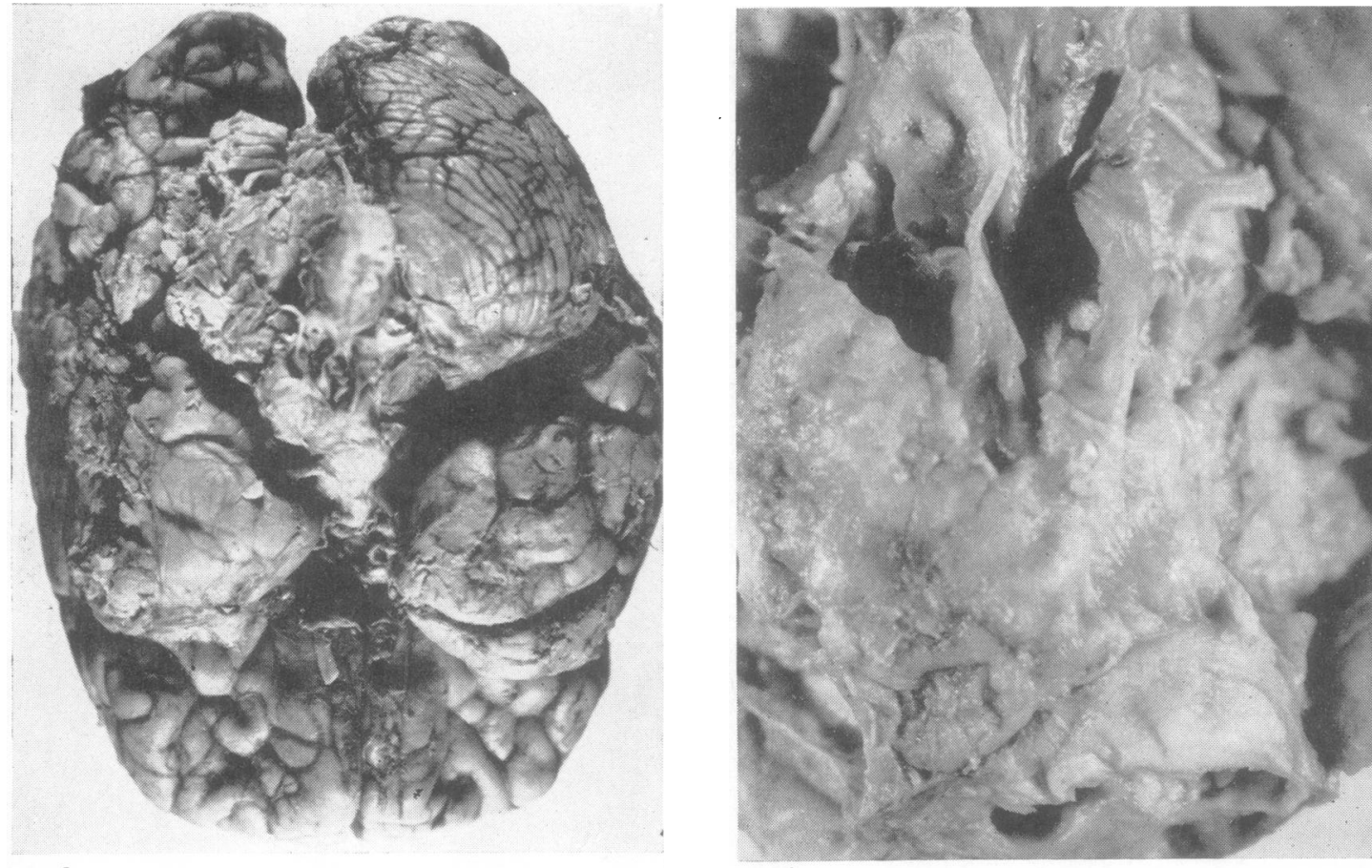

FIG. 3.

FIG. 4.

FIG. 3. Base of the brain. A mass of tumour extends backwards from the optic chiasma to the medulla.

FIG. 4. Tumour mass surrounding basilar artery. The two vertebral arteries can be seen running upwards into the tumoi

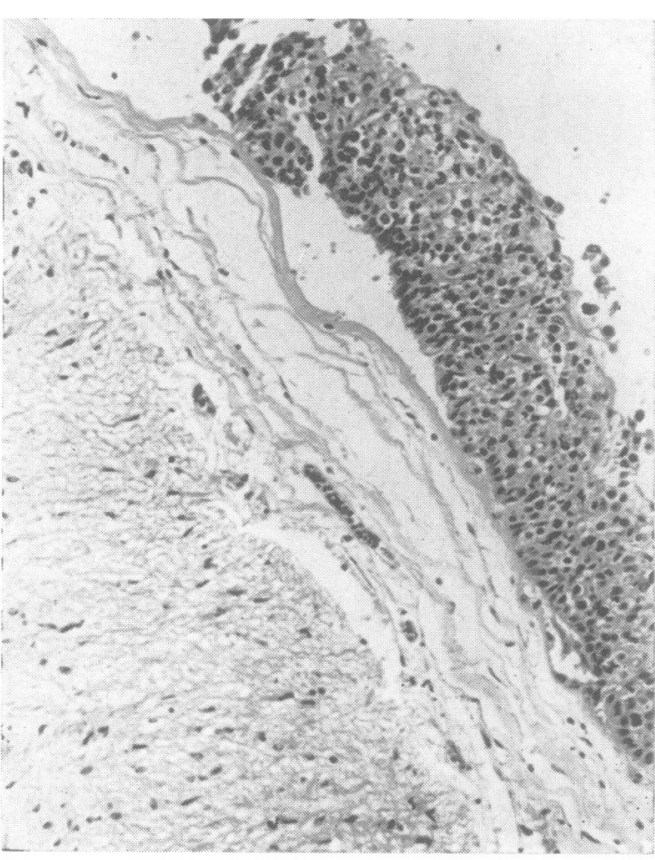

FIG. 5.

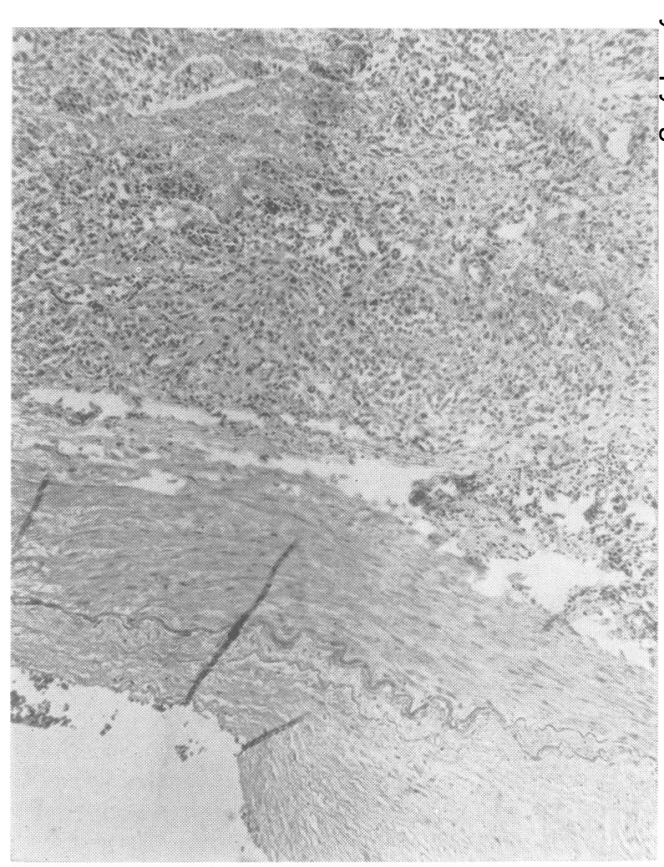

FIG. 6 .

FIG. 5. Diffuse infiltration of the meninges by squamous cell carcinoma. Haematoxylin and eosin $\times 115$.

FIG. 6. Tumour (above) surrounding basilar artery (below). Haematoxylin and eosin $\times 125$. 


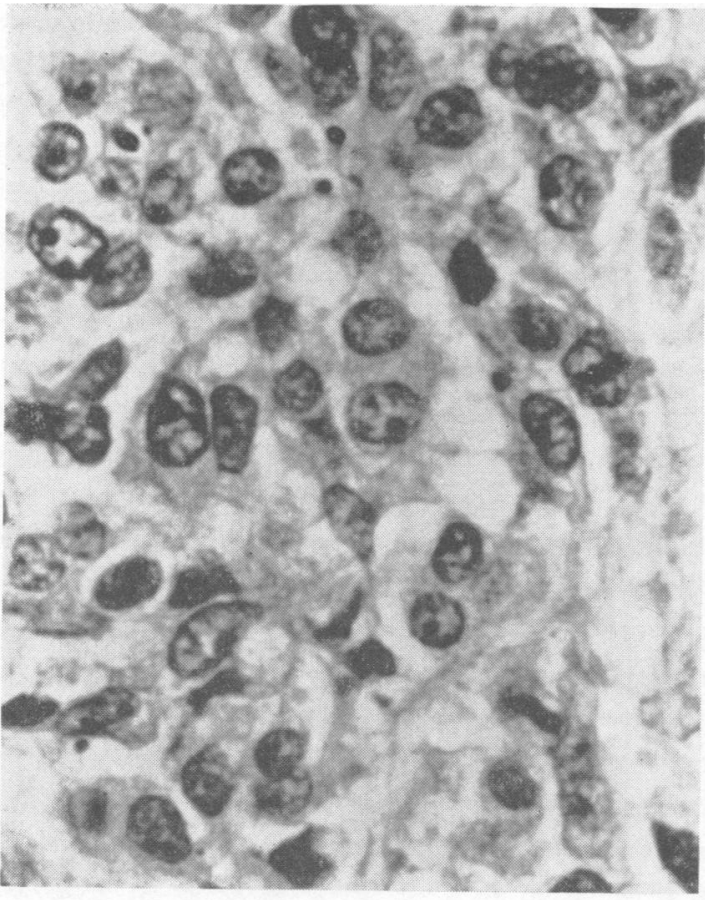

FIG. 7.

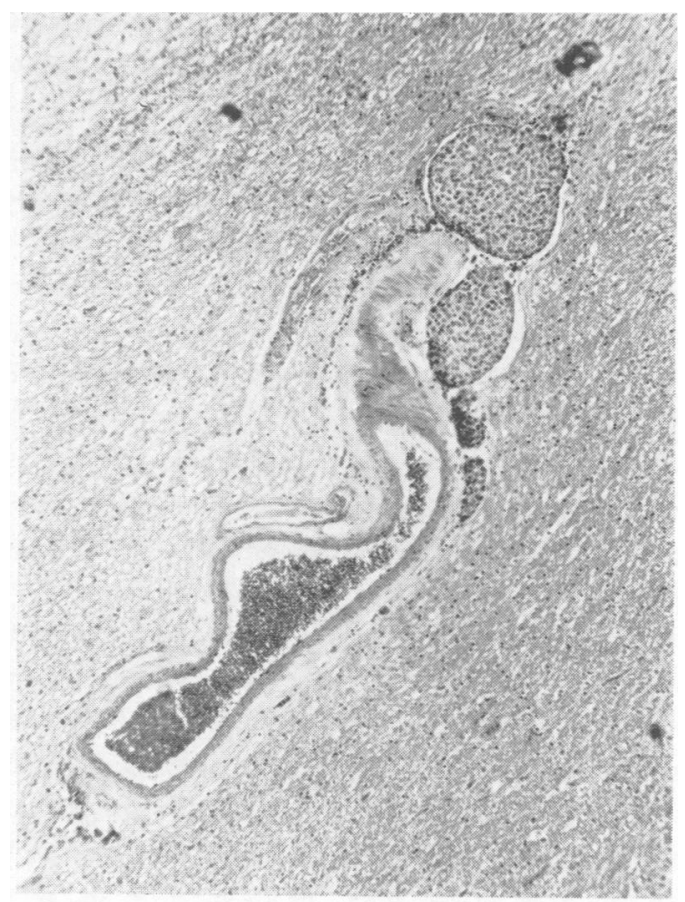

FIG. 8.

FIG. 7. High-power view of tumour mass around basilar artery. Haematoxylin and eosin $\times 850$.

FIG. 8. Clump of tumour cells in a paravascular space deep in the pontine substance. Haematoxylin and eosin $\times 125$.

overlying the anterior horn of the left temporal lobe was infiltrated by clumps of malignant cells (Fig. 5). The tumour mass overlying the pons and surrounding the basilar artery (Fig. 6) showed the histological appearances of a squamous cell carcinoma, being made up of cells, which although recognizably squamous in origin, showed all the usual cytological criteria of malignancy, i.e., nuclear and cellular pleomorphism, nuclear enlargement and hyperchromatism, and a moderate number of mitotic figures (Fig. 7). The degree of differentiation of the tumour varied considerably, in some areas it being very poorly differentiated and in other areas being formed of recognizable squamous cells. In no area was any obviously benign squamous epithelium seen. The tumour was surrounding the basilar artery, but not invading the arterial wall. There was no direct infiltration of the brain-stem, but tumour was seen deep in the pontine substance in a perivascular Virchow-Robin space (Fig. 8). In many areas there were small clumps of keratin flakes. The residual tumour seen macroscopically in the temporal lobe was formed almost completely by a mass of anuclear keratin flakes with only a few scattered clumps of epithelial cells. No evidence of tumour was seen elsewhere in the brain or meninges.

\section{DISCUSSION}

The macroscopic appearances of intracranial epi- dermoid cysts were first described by Cruveilhier (1829) who gave them the name 'tumeurs perlees'. In 1838 Müller described the microscopic appearances of the cysts and, noting that they frequently contain crystals of cholesterol, introduced the name 'cholesteatoma'. Critchley and Ferguson (1928) preferred the name 'epidermoid cyst' and this name is to be recommended, for not only does it describe accurately the true nature of the cyst but avoids confusion with the aetiologically different "cholesteatoma' of the middle ear. Intracranial cysts are of congenital origin, arising from ectodermal inclusions during embryogenesis (Remak, 1854; Critchley and Ferguson, 1928). The midline cysts probably arise from ectodermal elements included at the time of closure of the neural groove, but the laterally situated cysts more probably arise from ectodermal inclusions at a later stage of embryogenesis during the formation of the secondary cerebral vesicle (Russell and Rubinstein, 1963).

The cysts are usually considered to be entirely benign, though recurrences are common because surgical removal of the capsule is rarely complete. Nevertheless there have been eight cases reported in which a malignant tumour has developed. The 
first such case was described by Stromeyer (1910). The exact nature of the tumour this author described is in some doubt. He described a small-celled 'sarcoma' arising from an epidermoid cyst situated in the frontal lobe of the left cerebral hemisphere of a 49-year-old woman. The histological appearances were not illustrated and Henschen (1955) considered that the tumour was a glioblastoma arising in the immediate vicinity of an epidermoid cyst. Nevertheless the description given by Stromeyer is compatible with the tumour being an anaplastic squamous cell carcinoma, such tumours frequently being classified as sarcomata at the time of this report.

Ernst (1912) reported a case of a 51-year-old man in whom a poorly differentiated squamous cell carcinoma developed from an epidermoid cyst in the right cerebello-pontine angle. At necropsy the tumour was found to have infiltrated the pons, medulla, and rhomboid fossa. There was also spread into the ventricles and the leptomeninges of the brain-stem. This particular case was also described independently by Rossknecht (1913).

Hug (1942) described a man of 49 who had had symptoms of intracerebral tumour for 13 years. Necropsy revealed a squamous cell carcinoma that had originated in a parapontine epidermoid cyst and had spread into the left temporal lobe. Henkel (1951) described two further cases. Both were of squamous cell carcinoma developing in parapontine epidermoid cysts. One of the tumours showed widespread meningeal infiltration.

Yamanaka, Hinohara, and Hashimoto (1955) reported a case in which a cystic squamous cell carcinoma developed from an epidermoid cyst of the meninges of the base of the brain. There was widespread carcinomatous infiltration in the leptomeninges. The case described by Davidson and Small (1960) is unusual in that it is the only previous case in which the malignant change was diagnosed while the patient was still alive. Furthermore, their patient appears to be the only one successfully treated. He was a man of 46 with right frontal lobe tumour and a Foster-Kennedy syndrome. At operation an epidermoid cyst of the right frontal lobe was removed and the tumour was found to have diffusely infiltrated the right optic nerve. Histological examination showed that a moderately well-differentiated squamous cell carcinoma had developed in the epidermoid cyst and it was this malignant tissue that was infiltrating the optic nerve. The patient recovered following $x$-ray therapy.

Landers and Danielsky (1960) reported a case of a 73-year-old woman who lapsed into coma following abdominal surgery. Malignant cells were found in the cerebrospinal fluid and meningeal carcinoma was diagnosed, though the exact nature of the malignant lesion was not realized. At necropsy a tumour was found in the cerebellar vermis which was partially obliterating the fourth ventricle. Histologically the tumour was an epidermoid cyst in which a moderately well-differentiated squamous cell carcinoma had developed. There was widespread carcinomatous infiltration of the leptomeninges.

There appear then to have been eight previously reported cases in which malignant change has occurred in the squamous lining of an intracranial epidermoid cyst. In' only one of these cases is the origin or nature of the malignant tumour in any way doubtful. It must be accepted therefore that malignant change is a well-documented, though rare, complication of intracranial epidermoid cyst.

The case reported above is only the second such to be diagnosed while the patient was still alive, all the other cases having been diagnosed at necropsy. That malignant changes have occurred should be suspected in any patient with a known epidermoid cyst who fails to respond to removal of the bulk of the keratinous material or whose condition rapidly and suddenly deteriorates. The diagnosis can be confirmed on biopsy examination if membrane is obtained, though often this must be based on the appearances of only a few clumps of cells. These mayp or however, as in the case reported above, shov 응 sufficient criteria of malignancy for a diagnosis of carcinoma to be established. Even if the correct $c$ diagnosis is made during life the treatment is nod likely to be successful, mainly because of the para ticular tendency to global siting of the epidermoi $\Phi$ cyst and malignant invasion of the brain-stem. Nevertheless the patient reported by Davidson and Small recovered and was well following the removal of a malignant epidermoid cyst from the frontal lobe with subsequent $x$-ray therapy.

\section{SUMMARY}

The clinical and pathological details are given of a 43-year-old man in whom a squamous cell carcinoma developed from the epithelial wall of a longstanding intraventricular epidermoid cyst. This is the ninth such case reported in which malignant change has occurred and the previous reports are summarized.

We would like to thank Mr. R. T. Johnson for permission to quote the clinical details of this case, Dr. P. O. Yates for his help and advice, and Dr. R. Whitehead for reading the manuscript. We are indebted to $\mathrm{Mr}$. B. Figg for the photographs and photomicrographs.

\section{REFERENCES}

Critchley, M., and Ferguson, F. R. (1928). The cerebrospinal epidermoids (cholesteatomata). Brain, 51, 334-384. 
Cruveilhier, J. (1829). Anatomie Pathologique du Corps Humain, vol. 1, book 2, plate 6. Baillière, Paris.

Davidson, S. I., and Small, J. M. (1960). Malignant change in an intracranial epidermoid. J. Neurol. Neurosurg. Psychiat., 23, 176-178.

Ernst, P. (1912). Häufung dysontogenetischer Bildungen am Zentralnervensystem. Ver. dtsch. path. Ges., 15, 226-234.

Henkel, H. G. (1951). Besondere Formen bösartiger Erkrankungen der weichen Hirnhäute. Ver. dtsch. Ges. Path., 35, 185-188.

Henschen, F. (1955). Handbuch der speziellen Pathologische, Anatomie und Histologie, edited by $O$. Lubarsch, F. Henke, and $R$. Rössle. Bd. 13, teil 3, p. 648. Springer, Berlin.

Hug, O. (1942). Krebsbildung in einem pialen Epidermoid. Virchows Arch. path. Anat., 308, 679-689.

Landers, J. W., and Danielski, J. J. (1960). Malignant intracranial epidermoid cyst. Arch. Path., 70, 419-423.
Müller, J. (1838). Ueber den feineren Bau und die Formen der krankhaften Geschwülste, vol. 1, p. 50. Berlin.

Peyton, W. T., and Baker, A. B. (1942). Epidermoid, dermoid and teratomatous tumors of the central nervous system. Arch. Neurol. Psychiat. (Chic.), 47, 890-917.

Remak, R., (1854). Ein Beitrag zur Entwickelungsgeschichte Krebschaften Geschwülste. Dtsch. Klin., 6, 170-174. (Cited by Critchley and Ferguson, 1928).

Rossknecht, E. (1913). Häufung dysontogenetischer Bildungen im Zentralnervensystem. Inaug. Diss., Bergmann, Wiesbaden.

Russell, Dorothy S., and Rubinstein, L. J. (1963). Pathology of Tumours of the Nervous System, 2nd ed., p. 15. Arnold, London. Stromeyer, F. (1910). Uber ein mit Sarkom kombiniertes Cholesteatom des Gehirns. Beitr. path. Anat. allg. Path., 47, 392-398.

Yamanaka, A., Hinohara, S., and Hashimoto, T. (1955). Primary diffuse carcinomatosis of the spinal meninges accompanied with a cancerous epidermal cyst of the base of the brain. Report of a case of autopsy. Gann, 46, 274-276. 